\title{
TRANSITIONING IT PROJECTS TO OPERATIONS EFFECTIVEly in PUblic SECTOR: A CASE STUdy OF AUSTRALIAN GOVERNMENT AGENCY
}

\author{
Yaser Mirza $^{1}$ and Baber Majid Bhatti ${ }^{2}$ \\ ${ }^{1}$ Department of Information Technology \& Mathematical Sciences, University of South \\ Australia, Adelaide, Australia \\ ${ }^{2}$ Department of Information Technology \& Mathematical Sciences, University of South \\ Australia, Adelaide, Australia
}

\begin{abstract}
Operational effectiveness is measured by the application availability to end-users and the extent of convenient usage of the application to perform their business functions. This paper demonstrates how varying project transition process can affect the operational effectiveness. This explanatory case study uses various projects in a South Australian government agency as the candidates for evaluation. With various applications that existed in the production environment, the end-users had varying levels of satisfaction. This research analyses factors influencing the operational efficiency the projects in transition from project delivery into operations. The evidence clearly demonstrates criticality of the transition process of applications from project delivery phase to operations phase. The research analyses the findings specific to government agencies and presents recommendations. These findings can be useful to public sector agencies for improving availability of IT applications in operations.
\end{abstract}

\section{KEYWORDS}

Project transition, IT operations, Operational efficiency, Government, Information Technology, South Australia, Public Sector, Process improvement.

\section{INTRODUCTION}

The comparative case study report format has been used in this paper as it offers multiple perspectives in the analysis and allows new insights into the investigation [1]. In SAGOV (the anonymised fictitious name of the public-sector organisation in South Australia whose study is being presented here), the project delivery team is responsible for development, implementation and testing of the software applications. After deployment in the production environment, these applications are handed over to the IT operations team. The IT operations team is concerned with the operational effectiveness of applications, which is measured by: (1) the availability of those applications to the end-users, and (2) the extent of convenience to use for the business utility. At the time of this study, the transition process between the project delivery team and the operations team was mostly inconsistent, ad-hoc and was not standardised. Furthermore, with various applications currently existing in production, the end-users had different levels of unmanaged expectations due to which they had different opinions about the rating of IT operations efficiency.

In this case study, a literature review was first conducted to understand various aspects of the problem and their relevance to SAGOV. A logical hypothesis was then proposed and tested. 
Based on explanatory case study approach, different projects in SAGOV were selected as units of this case study to seek answers to the research questions presented in this paper. To keep the scope of this case study limited, it was assumed that the quality of applications delivered to the operations team was consistent.

Using Yin's explanatory program effects case study approach [1], the data was collected from various projects within SAGOV. Research surveys based on pre-defined questionnaires were also conducted. The data were then analysed to understand: (1) the effects of project delivery activities, and (2) the overall impact of those activities on the operational performance of the applications. Details of other data collection techniques which were used for understanding the impact of various events and processes on the operational outcomes, have been provided in the section 2.5. The patterns and relationships to the hypothesis have been derived in the context of SAGOV. Moreover, potential ethical dilemmas were also investigated and their mitigation has been proposed in this paper.

Four projects from SAGOV were selected as units of analysis for this case study. Using cross comparison between those units, the impact of project transition process on the operations efficiency was evaluated. The findings clearly demonstrate that the project transition process critically impacts the operations efficiency of IT applications. These findings can be useful for SAGOV for improving the availability of software applications to the business.

\section{ISSUE IDENTIFICATION AND ANALYSIS}

SAGOV had several new and legacy applications running in parallel which had rendered the production environment very complex, comprising various platforms and diverse technologies. With the passage of time, the number of applications and the complexity of production environment grew. In many cases new applications co-existed with the old ones, making the job of operations staff more challenging with every new release. The situation was quite similar to that mentioned by Dibling [2], who considers complexity of the production environment as hostile to the applications; the stress and the tests that an application goes through in production environment are far more difficult than those in pre-production/project lifecycle. The probability of defects in the applications in production is high because of complicated nature of the environment and the fact that defects are known unknowns [2]. The operations team comprises a relatively larger number of IT resources as compared to the project delivery team and is often held responsible for the application failures or poor availability. The operations team is expected to provide uninterrupted availability of the IT applications to the business [3]. With increasing complexity in the scope of integration in the operational space, various organizations are finding it difficult to maintain the applications availability despite a lot of effort and investment to keep the applications availability high [4]. This explains why IT is often considered an expensive overhead by the business executives [5]. At the time of this study, IT in SAGOV was also going through such an era.

\subsection{Research Questions \& Study Propositions}

After literature review and initial analysis of phenomenon of interest, the following research questions were compiled.

1. Does operational efficiency have a dependency on the transition process?

2. What are some of the factors affecting the transition process?

3. How can it be improved? 
Vol. 8, No. 1, March 2017

These research questions were evaluated using the data gathered through surveys and interviews the questionnaires of which are present in the Appendix $1 \& 2$.

\subsection{Unit of Analysis \& Justification}

To verify if there is an influence of project transition process on IT operational effectiveness at the SAGOV, an initial survey was conducted. The respondents were asked to illustrate their level of agreement with the proposed relationship as described in the Appendix 1 (Survey Question 1). A total of sixteen people responded to the survey including the manager for project delivery team, manager of IT operations team and users from technical and business functions.

Summary of the response is given below:

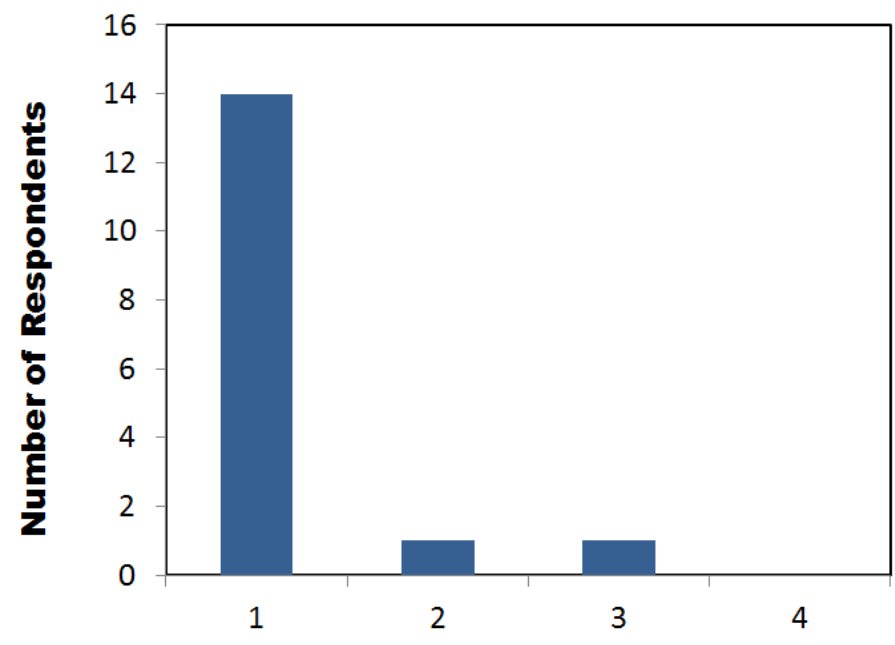

Response Score Allocated

Figure 1. Survey responses representation

Legend: Strongly Agree $=4$, Agree $=3$, Don't Know $=2$, Disagree $=1$

Table 1: Survey response scores.

\begin{tabular}{|c|c|}
\hline Response Score & Number of Responses \\
\hline 4 & 14 \\
\hline 3 & 1 \\
\hline 2 & 1 \\
\hline 1 & 0 \\
\hline
\end{tabular}

Historic information was used from four IT projects which had gone into production in SAGOV. The selection criteria for these projects comprised a certain level of success or failure in the operational environment based on the feedback from end-users and operations staff who maintained the applications. Those application were selected which had exited from production and the perception about their relative success or failure was clear across the organisation. The selection criteria were established in accordance with the opinion of business and operations staff which they depicted in a survey. The response of this survey is summarized as follows: 
International Journal of Managing Public Sector Information and Communication Technologies (IJMPICT)

Vol. 8, No. 1, March 2017

Table 2: Application scores from Business and IT perspective.

\begin{tabular}{|l|c|c|}
\hline $\begin{array}{l}\text { Project } \\
\text { Name }\end{array}$ & $\begin{array}{l}\text { Average Application score from } \\
\text { business perspective }\end{array}$ & $\begin{array}{l}\text { Average Application score from } \\
\text { IT operational support } \\
\text { perspective }\end{array}$ \\
\hline Alpha & 27 & 31 \\
\hline Bravo & 76 & 25 \\
\hline Charlie & 37 & 70 \\
\hline Delta & 81 & 77 \\
\hline
\end{tabular}

Hypothetical names for these projects have been used for the sake of anonymity. A brief about these four selected projects is as follows:

Project ALPHA: Considered as an operational bottleneck by the end-users and declared as difficult to maintain by the operations staff.

Project BRAVO: Considered as reasonably acceptable by the end-users but declared as difficult to support by the operations staff.

Project CHARLIE: Considered as reasonably maintainable and supportable by the operations staff but not seen as meeting business objectives by the end-users.

Project DELTA: Considered as a successful business application by the end-users, and the operations staff were comfortable to support and maintain.

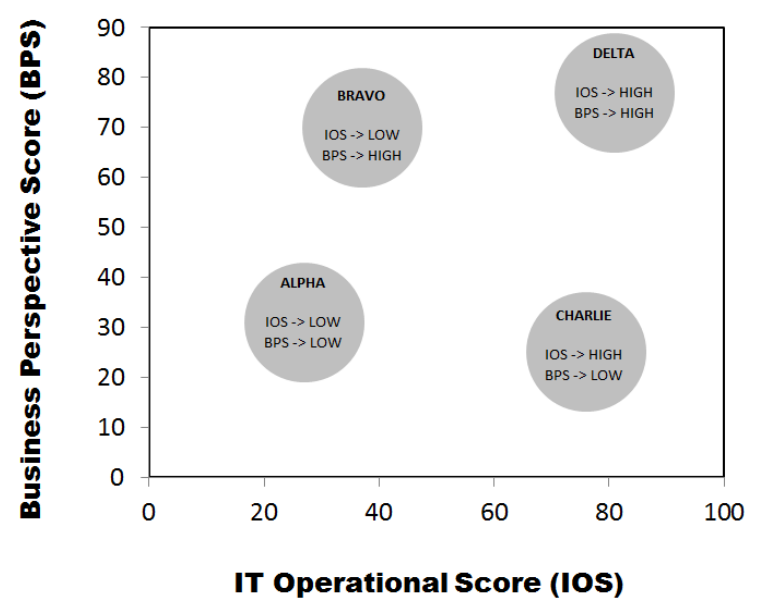

Figure 2. Representation of Applications from Business and IT perspective.

The analysis performed on above projects was conducted to evaluate the hypotheses and justify the outcomes of this case study.

\subsection{Limitations/constraints}

Although in general, the project selection was agreed upon by different interviewers but there were occasions when a couple of candidates did not agree completely with the categorization of Bravo and Charlie project. This introduced the risk of error in the future investigation stages, because the opinion of interviews during the interviews could impact the findings of this study. 


\subsection{Data Collection Strategies \& Limitations}

Different sources for collection of the data were used in this case study. The selection of projects was also a critical aspect in this case study. The details of project selection and the data collection along with the associated limitations are briefly discussed below:

Table 3: Data collection strategies used during case study.

\begin{tabular}{|c|c|c|}
\hline Data Collection Strategies & Details & Possible limitations / constraints \\
\hline Interviews & $\begin{array}{l}\text { Semi-structured interviews } \\
\text { were the primary data } \\
\text { collection method. Target } \\
\text { audience for the interview } \\
\text { were: } \\
\text { Individuals leading project } \\
\text { and operations groups, } \\
\text { project managers, } \\
\text { pperations technical } \\
\text { application admin, manager } \\
\text { of strategy \& architecture } \\
\text { branch who is involved in } \\
\text { the project initiation and } \\
\text { engagement with vendors }\end{array}$ & $\begin{array}{l}\text { It was difficult to obtain interview } \\
\text { appointments from all stakeholders in } \\
\text { the process due to their various other } \\
\text { commitments. } \\
\text { The target audience of the interview } \\
\text { may be incomplete and may not } \\
\text { include stakeholders which may have } \\
\text { been incorrectly assessed as } \\
\text { nonessential stake holders in the } \\
\text { transition process. }\end{array}$ \\
\hline Direct Observations & $\begin{array}{l}\text { Direct observations were } \\
\text { very effective in the data } \\
\text { collection as the span of } \\
\text { direct observation started } \\
\text { from over one year ago } \\
\text { which was much longer } \\
\text { than the timeline of case } \\
\text { study. It was advantageous } \\
\text { to reduce time to understand } \\
\text { the process details and drill } \\
\text { down to data sources with } \\
\text { more ease. }\end{array}$ & $\begin{array}{l}\text { As human judgement was involved in } \\
\text { the process there was a possibility of } \\
\text { a mistake. } \\
\text { Possibility of introduction of bias due } \\
\text { to longer duration spent in the } \\
\text { organization with vulnerability of } \\
\text { being influenced by various factors to } \\
\text { build up a perception. }\end{array}$ \\
\hline Documentation & $\begin{array}{l}\text { Various forms of } \\
\text { documentation were } \\
\text { considered relevant for the } \\
\text { case study and were } \\
\text { consulted. Example of such } \\
\text { documentation are: } \\
\text { Project Support Matrices, } \\
\text { Transition Hand over } \\
\text { documents, Electronic } \\
\text { Repositories for Projects } \\
\text { (In-house Wiki), Non- } \\
\text { functional Requirements } \\
\text { document, Vendor } \\
\text { Contracts for project } \\
\text { delivery }\end{array}$ & $\begin{array}{l}\text { It was difficult to go through all } \\
\text { documents as it was very time } \\
\text { consuming and it had to be limited to } \\
\text { a certain point. } \\
\text { Set of documentations for different } \\
\text { projects had variations which made it } \\
\text { difficult to compare the documents. It } \\
\text { would be more obvious where } \\
\text { different projects had used different } \\
\text { implementation strategies with } \\
\text { different vendors. }\end{array}$ \\
\hline
\end{tabular}




\section{CAUSE AND EFFECT SUMMARY}

Some of the causes that came up as outcomes of the research are mentioned in this section along with the summary of their effects:

\subsection{Cause 1: Project Resourcing Methodology}

Cause: As the information surfaced during the case study, it became more evident that the project resources were contractors in most of the cases and had their funding associated with the project. Once the project was handed over to operations, the project delivery phase was officially completed and the resources were released. Any further funding or resource requirements from that point onwards was the responsibility of the operations team.

Effect: Because of this resourcing mechanism, once the applications went into production, all the project resources having knowledge about the applications and their domain were released. This introduced a vacuum of knowledge which was very hard for the operations group to fill on their own at later stages to support the application.

\subsection{Cause 2: Inadequate communication between the two functional groups}

Cause: From the evidence collected in the case study it was evident that there was a significant communication gap between the operations and project delivery teams, and that there were no set processes that allowed post-production resources to be allocated to the project team.

Effect: This left the operations group with no visibility into the project and the final product until the time when the application was handed to the operations team.

\subsection{Cause 3: Ad-hoc support processes across the organisation}

Cause: Different stakeholders were inquired about the limitations in the operations requirements. Some of them showed the concern that the operations team was not able to define the requirements for production support as different projects were treated very differently in terms of support.

Effect: Due to this there was no inconsistency in the processes, which led to considerable dependency on the production support resources and their indigenous support based on individual knowledge.

\subsection{Cause 4: Lack of a resource pool between Operations and Project Delivery Services teams}

Cause: One of the senior project managers in the interview suggested that there were no overlapping resources between the two teams who could oversee the application throughout its lifecycle. A distinct group of resources was involved in early part of the lifecycle while altogether another group looked after the application in the later part of its lifecycle.

Effect: It was a big gap and could be the root-cause of multiple problems during the operations support when the right people with domain and application knowledge were sought. 


\subsection{Cause 5: Ineffective Handover}

Cause: The case study revealed a sizeable dependency of the success of operations support on the quality of documents and handing over of the application from project delivery team to the operations team.

Effect: It was observed that the handing over in many cases was not very effective. In some cases, the handing over was not even completed. Hence, incomplete or ineffective handovers led to inability of the operations team to provide robust application support. This fact was further exacerbated by the expectation of business that the operations team would cope up with the production support issues.

\subsection{Cause 6: Reactive Organisational Culture}

Cause: An interesting observation made during the case study analysis was that the operations team, being the on-going permanent staff in the organization, adopted a reactive strategy not to participate into processes and initiatives unless it was utmost important and there was no way out without doing it.

Effect: This response from the operations team worsened the collaboration and communication gaps between the project delivery and operations teams and consequently resulted in several problems at later stages.

\section{Proposed Solutions}

For evaluation of the various causes, following survey question was asked for gathering the information:

"What is the biggest impediment in application support with respect to the transition process? Rate the factors from 1-4 where the biggest impediment is given 4 and the smallest is given 1 score." The details of this survey question are available in the Appendix under survey question 3.

The response is summarised in the figure and table below:

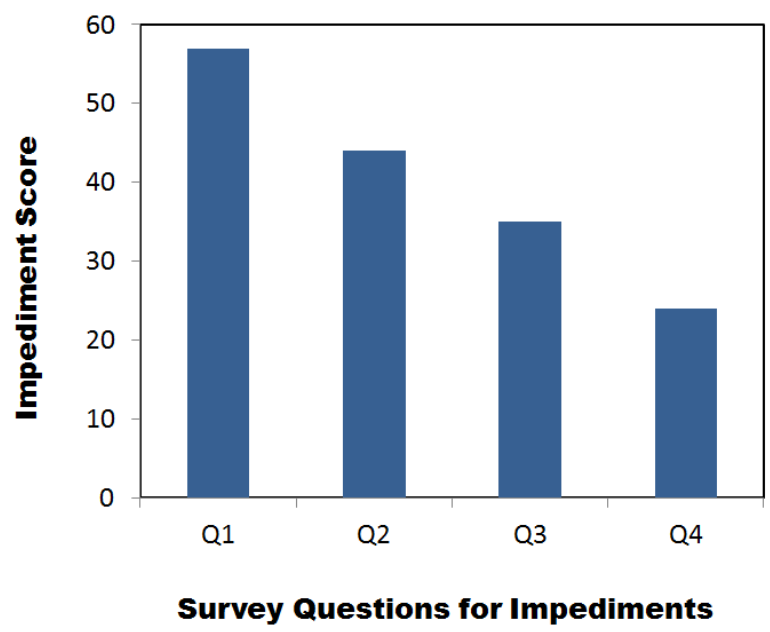

Figure 3. Impediments ranking from survey responses. 
Vol. 8, No. 1, March 2017

Table 4: Impediments scores.

\begin{tabular}{|l|l|l|}
\hline$\#$ & Impediment & Score \\
\hline Q1 & Absence of resources at the time of transitioning for knowledge transfer & 57 \\
\hline Q2 & $\begin{array}{l}\text { Absence of standard processes and templates required for adequate applications } \\
\text { support }\end{array}$ & 44 \\
\hline Q3 & Insufficient handover to operations team from the project delivery team & 35 \\
\hline Q4 & Lack of communication and collaboration across different areas & 24 \\
\hline
\end{tabular}

Given below is a description and evaluation of a range of different solutions that can solve the research problem:

\subsection{Change in Project Resourcing Methodology}

A possible solution to this problem can come from looking at the resourcing mechanism of another project.

It comes back to the project delivery where resources are acquired and retained in a way that their engagement stretches across the complete lifecycle of a project to some extent and not only limited to the delivery stage. Once the project is delivered to operations the resources should stay to support the initial operational functions because they are the ones who carried the domain and functional expertise. This will include considering different options of maintaining resource pools. Thus, critical resources in the project should stay in the organisation on a longer term. Besides providing support on the delivered projects, future projects can also be looked after by a subset of the same resource pool within the organisation.

This solution maybe a bit more complicated than it appears initially because it has got a lot of financial implications associated with it. As the case study belongs to a government organisation, the funding is approved by cabinet for projects and other IT initiatives based on their expected benefits and business outcomes. Since the funding is approved specifically for delivery of certain projects, the operations fall under a different umbrella of funding which means that it is very difficult to merge the funding streams from project delivery to operations for enforcing the common business objectives. Although this solution seems to be the most effective but under the given circumstances and government policies, it is very difficult to implement a solution of this sort.

\subsection{Managing Operational Requirements in Project Delivery stage}

Kellow et al. [6] suggests that there should be a formal mechanism of including the operational requirements into the project deliverables and a directory of such supporting material should be accessible to the operations staff. According to Westland [7], these deliverables need to be referred to in the project closure report and supporting documentation should be available for acceptance. Thus, if the operations team is handed over the deliverables required for running an application, and they formally accept the deliverables after ensuring that they have all the information required for the support of the applications, the support can be expected to run relatively smoother after that.

One of the proposed solutions is to introduce resources from different stages of the project lifecycle including operations and implementation teams in the project delivery right from the project initiation. It also encourages involving stakeholders from business in defining the requirements of the project right from the project initiation stage. Mcmanus \& Wood-Harper [8] look at the scenario from a lifecycle perspective and try to elaborate different stages in the 
waterfall model where the operations and the project delivery teams collaborate to achieve the best outcomes for post-production operational efficiency. They suggest that this collaboration should start from the feasibility stage of the project where stakeholders have more willingness to define the details of deliverables. In the design stage when the technical designs are being put into place, project teams should also enrich the supporting documents which should be handed over as part of the deliverables along with the application at the closure of the project [8].

It means that the operations team gets a chance to get their desired inputs, in terms of knowledge required for operational support, right from the start and the project delivery team can include those details as deliverables of the project. This may include design documents, test cases, support documentation, users' manuals and functional specifications which are understandable and comprehensible by the business and support users. The project delivery team can consolidate the whole set of requirements in a central repository which is accessible by all stakeholders within the organisation for review and changes. The deliverables can be negotiated and worked upon during the project delivery stage before it is too late and resources are released. Actions from all levels in the organisation are expected, starting from the top management, to enforce defining of commitments and expectations in the early stage of project.

As most of the project resources are contractors which are relieved after the project delivery, it is recommended that the induction kit of the project managers and the project resources include these requirements and set the expectations right from their initial engagement in order to avoid the surprises later.

\subsection{Common resource pool between Operations and Project Delivery teams}

An alternative solution can be looking at a very small set of resources who can act as a bridge between projects and operations. These will be specific resources that understand the operational complications and also know the constraints in project delivery.

Based on the interviews conducted with senior project managers, it was found that using a quality assurance team to look after the project as well as operations makes more sense because of their role which is logically involved in pre-production testing along with post-production issues and support.

\subsection{More Effective Handover}

In one of the case studies of project post-mortems conducted by Westland [7], one evident reason of project failure into operations was attributed to be the handing over of project to operations staff before its completion and handing over of deliverables to the operations team. It again is an example of a situation where lack of information transfer from project team to the operations team resulted in failure in the production.

Setting up repeatable processes for implementation and production support by the operations staff can help bridging the knowledge and communication gap [9]. Obviously operational staff in most cases will not be able to do it independently on their own until they are either supported by the project team or enabled to an extent that they can take the task on their own. Minnock [9] also emphasises on end-user trainings based on the argument that information systems are most likely to become a problem for the end-users because of the lack of training. This may or may not result in the downtime of the applications but will impact the business outcomes due to inefficiency of business transactions. Gupta \& Qureshi [10] state that availability of the information about requirements can significantly reduce the associated downtimes. 
Proper entry and exit criteria should be agreed and setup for various activities of the project during the planning stage, and the deliverables should be agreed by both the project team and the operations team during the implementation stage. At handover stage, there should be an agreement that initial support of the application shall be provided by the project team, followed by a formal handover of the application to the operations team only after ensuring that the latter is equipped with sufficient knowledge and skills to support the application on their own [8].

\subsection{Change in Organisational Culture}

One important consideration is a change in the overall reactive culture of the organisation. It involves clarity in the roles of different groups. One of the bottlenecks highlighted by different stakeholders during the interviews in this research was the laid back and reactive approach among the operations team. Although the other functional groups had a perception about this reactive approach of the operations team, but when the question was put in front of the operations team during the research, it was found out that they viewed it as a case of unrealistic expectations. It was inferred that other functional groups must realise the job specification of the operations staff. Hence, it means that the clarity about roles and responsibilities has to be achieved across the organisation. Minnock [9] looks at a very different aspect of production support stating that (1) managing expectations of the end-users and (2) implementing change management is also critical for the success of applications in operations, and allows a better transition from pre-production to post-production phases. Nizami \& Surdek [11] emphasise on putting in visible practices to all groups. A central governing body should be there to ensure various levels of communication between the project delivery and operations teams, thus ensuring minimal gap in the expectations. A certain level of service quality can be achieved by implementing best practices, standards and policies along with collaboration processes among the departments [3]. There was a time when IT and business did not converse but now the ownership of many systems is a shared responsibility between business and IT operations teams [12].

These recommendations may help reducing the problem to some extent but are definitely not a complete solution, and hence should be looked at as part of the solution.

\subsection{The Overall Solution}

To be more effective in any given scenario, a solution is expected to be implemented in the form of a program comprising combination of the initiatives mentioned in above sub-sections. Such a program can be called "Application Sustainability Lifecycle (ASL)". The scope of initiatives included in this program may vary depending on the implementation capacity and business priorities.

The ASL program may include but is not limited to the following projects/initiatives:

1. Project-Operations Transition Support Group (POTS Project)

2. Support Process Streamlining Project (SPS Project)

3. Handover Process Improvement Project (HPI Project)

4. Cultural Change Management Project (CCM Project)

Details of the proposed solution implementation are discussed in the section: Action Plan. 
International Journal of Managing Public Sector Information and Communication Technologies (IJMPICT) Vol. 8, No. 1, March 2017

\section{ACtion Plan}

Given below is an approach for implementation of the recommended solution. For the sake of comprehensiveness, the action plan has been presented in the terms of What, When, How, Who.

\subsection{What}

Although different solutions have been proposed which can help solving the problem, yet a careful combination of those should be implemented to complement the effect of each other and improve the operational efficiency (see Table 1).

Table 5. Application Sustainability Lifecycle Program (ASL Program)

\begin{tabular}{|l|r|l|}
\hline Project & Scope \\
\hline Project 1: Project-Operations & 1. & Common Resource pool allocation \\
Transition Support (POTS) & 2. Extension of Operations Resources into Projects \\
Project & 3. Extension of Project Resources into Operations \\
\hline Project 2: Support Process & $\begin{array}{l}\text { 1. } \\
\text { Streamlining (SPS) Project }\end{array}$ & 2. $\begin{array}{l}\text { Educating the stakeholders about the standard } \\
\text { processes }\end{array}$ \\
& 3. $\begin{array}{l}\text { Establishing templates for support requirements of } \\
\text { various project types and deliverables }\end{array}$ \\
& 4. Establishing central support repositories \\
\hline Project 3: Handover Process & 1. $\begin{array}{l}\text { Defining operational requirements in project } \\
\text { deliverables }\end{array}$ \\
Improvement (HPI) Project & 2. Implementing transition and handover checklists \\
& 3. $\begin{array}{l}\text { Standardising testing procedures and minimum scope } \\
\text { of testing for acceptance of any project of a type within } \\
\text { the organisation }\end{array}$ \\
\hline Project 4: Cultural Change & 1. $\begin{array}{l}\text { Promoting Proactive culture } \\
\text { Management (CCM) Project }\end{array}$ & 2. Promoting collaboration between two functional groups \\
\hline
\end{tabular}

\subsection{When}

Subject to the approval of the business case for ASL program, availability of resources, funding and organizational priority, and this project should be implemented as soon as possible. It should start from planning the desired application portfolio in operations and then the solutions should be implemented. Once the processes are defined and approved, they can be implemented on the ongoing projects from that point onwards.

\subsection{Who}

It is recommended to make an ASL taskforce which will include critical in-house resources from both the operations and project delivery teams. Additional resources should also be acquired as deemed necessary to deliver the project scope. A dedicated program manager should be considered for looking after the project. Specialized process improvement resources should be consulted in the project and if required, an external specialist vendor in the space should be looked out for consultancy and advice.

\subsection{How}

The first step would be to draft a business plan demonstrating ROI on the program and high level requirement of budget and resources. Once the business case is approved, the program should be 
kicked off formally. All projects in the program scope of work should be implemented following the formal project management methodologies. Baseline detailed specifications and project plans should then be defined. All the projects in a program may not be required to run simultaneously but given the feasibility of different initiatives, a staged implementation can help in managing changes without surprises.

The staged implementation plan will start with actions that will proactively create awareness in the organization for subsequent directions. The initiative must take a top-down approach where directions originate from the top management. A simultaneous bottom-up approach must also take place for implementing those decisions by the technical resources who report the outcomes in the upward direction.

\subsection{Costs}

The business should be willing to take up cost of the programs provided that a business case is provided to them for each program showing the expected benefits to the business, which should be quantifiable improvement in the operational efficiency. An ROI of the project must be calculated and presented to the business against which the estimated costs can be approved for the project. Due to the overlapping nature of the program between projects and operations, the budget can be shared between funding pools of operations and project delivery.

Since the program of work should consider retaining the critical project resources for a period of time until operations team becomes self-sufficient, the program sponsors must be apprised early about baring the associated costs. This requires early and accurate budgets, but the challenge is to estimate the overall program costs at the business-case stage as the detailed requirements and scope of the program come at later stages.

\section{ETHICAL ISSUES}

The ethical issues can be looked at in three different ways:

1. Actual ethical issues

2. Perceived ethical issues

3. Potential ethical issues

\subsection{Ethical Issue 1 - Category: Actual / Perceived}

Since the researcher was a part of the organization, this fact could have possibly introduced a few ethical issues. One of the possible ethical issues could be biasness in the research because of the affiliation of the researcher to a specific functional entity with the organisation, which was project delivery team in this case. Hence, there could be a possibility of natural inclination of the opinion towards the department of affiliation. The case study was a careful attempt to understand the relationship and the functional behaviour of project transitions between the two organizational groups, i.e., project delivery and operations team. Thus, being part of one of the groups came with a conflict of interest.

Although this constraint was initially recognised and a conscious effort was made to exclude the biasness from this case study, but it is important to highlight the risk in such case studies.

The researcher went through proper ethical decision-making principles and maintained documented evidence of the feedback and interviews, which would clearly substantiate the opinions of different stakeholders involved in the process in a very transparent manner. 


\subsection{Ethical Issue 2 - Category: Potential}

Another very important aspect to be considered when considering ethical issues could be the desensitizing of information in this regard.

As the nature of the organisation was clearly sensitive and critical, reasonable measures must have been taken to ensure that the information was presented in the most suitable way where no stakeholders were affected, and the organisational sensitivity to information release and security policy was not breached.

To assure prevention of the above-mentioned ethical issues, the researcher undertook management review of the research documentation. Prior to conducting the research, the researcher had taken written consent from management of the organisation to conduct the research and that the information met the sensitivity criteria and was presented to the right audience in the right way. Additionally, an internal supervisor to the research was appointed by the organization who was responsible for assuring that the information presented outside the organisation met the standards and the security policy of the organization.

\section{CONCLUSIONS}

The case study shows how operations efficiency can be affected by the transition process of projects from delivery to operations phase. The case study evidence clearly demonstrates the criticality of the transition process. Supported by the research published by Chris Neal [4], who is the CEO of BlueStrip Software emphasizes on the gap created by the lack of visibility of operations team into the project delivery which in turn results in poor availability of the IT applications after being handed over to the operations team [4]. This gap of knowledge and visibility is an evidence of the fact that adequate deliverables and documentation were not provided to the operations team during handover. According to Cagley [13] and Deutsch [14], project closure is the most neglected project management practice. Kellow et al. [6] states that often minimum information is received by the operations team as their involvement and communication with the project team in many instances is almost non-existent. Baysal [15] states that an information model is required for robust information exchange processes to exist. The absence of such a model results in a situation where the expectations of operations team are not clear to the project delivery team. Consequently the deliverables on which project teams are working are not known till the time they are delivered, which often results in surprises.

Future research: The case study can be looked at as a first step towards the solution of the problem and further research within as well as beyond the organisation is encouraged. The units of analysis can also be further diversified to understand the cause and effect of the phenomena covered in this case study. Quantitative analysis of the data can also be considered to reinforce the study outcomes and provide more concrete evidence to the relationships of interest. Another extension to this study could be varying the quality of project deliverables and understanding its effect on the operations outcomes in different ways, this may also help to isolate the process related issues from application quality related issues.

Furthermore, work can be done to eliminate the potential ethical issues from the case study. This will require more detailed work and time spent on different aspects of case study to ensure that correct processes are followed and that the ethical issues in this research are prevented.

Based on the current findings of this case study, there seems to be sufficient evidence to substantiate measures towards bridging the gaps pointed out in this paper. One of the first actions recommended is to prepare a full business case for Application Sustainability Lifecycle (ASL) 
International Journal of Managing Public Sector Information and Communication Technologies (IJMPICT)

Vol. 8, No. 1, March 2017

program. This business case can demonstrate the feasibility of ASL program from business perspective.

\section{REFERENCES}

[1] R. Yin, Case study research: design and methods, 3rd ed. Thousand Oaks, California: Sage Publications, 2003, pp. 109-140.

[2] J. Dibling. Debugging production software. Dr.Dobb's Journal 30(6), pp. 42-42,44,46. 2005. Available:

http://access.library.unisa.edu.au/login?url=http://search.proquest.com/docview/202693258?account id=14649.

[3] M. Govekar. The long road ahead to IT operations maturity. Computing pp. 17. 2008. Available: http://access.library.unisa.edu.au/login?url=http://search.proquest.com/docview/212390798?account $\mathrm{id}=14649$.

[4] N. Eddy, "Application Management Hinders IT Operations Report", eWeek, 2012. [Online]. Available: http://www.eweek.com/enterprise-apps/application-management-hinders-it-operationsreport. [Accessed: 22-Jun-2016].

[5] R. Reid. IT operations fight to demonstrate worth. Network World Canada 13(6), 2003. Available: http://access.library.unisa.edu.au/login?url=http://search.proquest.com/docview/198840668?account $\mathrm{id}=14649$.

[6] W. Kellow, J. O'Keefe Jr and G. Swanberg. Disciplined transition from projects to operations. AACE International Transactions pp. PM61-PM69,PM610. 2005. Available: http://access.library.unisa.edu.au/login?url=http://search.proquest.com/docview/208176888?account $\mathrm{id}=14649$.

[7] J. Westland, Project management life cycle, 1st ed. London: Kogan Page, 2007.

[8] J. Mcmanus and A. Wood-Harper, Information systems project management. Harlow: Financial Times Prentice Hall, 2003.

[9] S. Minnock. Go Live! Software Implementation. Construction Accounting \& Taxation 14(5), pp. 11-15. $2004 . \quad$ Available: http://access.library.unisa.edu.au/login?url=http://search.proquest.com/docview/232075277?account $\mathrm{id}=14649$.

[10] A. Gupta and S. Qureshi, "Collabra: A framework for cooperative Software Maintenance", in International Conference on Information Society, 2011, pp.133-138.

[11] K. Nizami and S. Surdek. Global software development and delivery. Dr. Dobb's Journal 32(8), pp. 22-26,28. $2007 . \quad$ Available: http://access.library.unisa.edu.au/login?url=http://search.proquest.com/docview/202682012?account $\mathrm{id}=14649$.

[12] W. B. Causey and B. Thielbar. Merging the IT/Operations silos. Electric Light and Power pp. 4041. $2012 . \quad$ Available: http://access.library.unisa.edu.au/login?url=http://search.proquest.com/docview/927669587?account $\mathrm{id}=14649$.

[13] M. Chemuturi and T. Cagley, Mastering software project management, 1st ed. Ft. Lauderdale, Fla.: J. Ross Publishing, 2010.

[14] M. S. Deutsch, "An exploratory analysis relating the software project management process to project success," in IEEE Transactions on Engineering Management, vol. 38, no. 4, pp. 365-375, Nov 1991.

[15] M. M. Baysal. "Functional and Behavioral Product Information Representation and Consistency Validation for Collaboration in Product Lifecycle Activities," Order No. 3509957, Syracuse University, Ann Arbor, 2012. 
International Journal of Managing Public Sector Information and Communication Technologies (IJMPICT)

Vol. 8, No. 1, March 2017

\section{Appendix 1: Survey Questions}

Number of staff surveyed 16 including Manager for project delivery team, Manager IT operations and technical and business users.

\section{Question 1}

There is an influence of project transition process on the IT operational effectiveness at the SAGOV. Do you agree or disagree with this statement and to what extent?

\begin{tabular}{|l|l|l|l|}
\hline Strongly Agree $=4$ & Agree $=3$ & Don't Know $=2$ & Disagree $=1$ \\
\hline
\end{tabular}

\section{Question 2}

Score the following IT application from IT business perspective and IT operational support perspective out of 100 .

\begin{tabular}{|l|c|c|c|c|}
\hline & Alpha & Bravo & Charlie & Delta \\
\hline IT business perspective & $/ 100$ & $/ 100$ & $/ 100$ & $/ 100$ \\
\hline $\begin{array}{l}\text { IT operational support } \\
\text { perspective }\end{array}$ & $/ 100$ & $/ 100$ & $/ 100$ & $/ 100$ \\
\hline
\end{tabular}

\section{Question 3}

What is the biggest impediment in application support with respect to the transitioning process? Rate the factors from 1-4 where the biggest impediment is given 4 and the smallest is given 1 score.

\begin{tabular}{|l|c|c|c|c|}
\hline Biggest Impediment & \multicolumn{3}{|c|}{ Rating } \\
\hline $\begin{array}{l}\text { Absence of resources at the time of } \\
\text { transitioning for knowledge transfer }\end{array}$ & 4 & 3 & 2 & 1 \\
\hline $\begin{array}{l}\text { Absence of standard processes and } \\
\text { templates required for adequate applications } \\
\text { support }\end{array}$ & 4 & 3 & 2 & 1 \\
\hline $\begin{array}{l}\text { Insufficient handover to operations team } \\
\text { from the project delivery team }\end{array}$ & 4 & 3 & 2 & 1 \\
\hline $\begin{array}{l}\text { Lack of communication and collaboration } \\
\text { across different areas }\end{array}$ & 4 & 3 & 2 & 1 \\
\hline
\end{tabular}

\section{Appendix 2: Interview Questionnaire}

The interview questionnaire comprised of the following fifteen questions:

1. There is an influence of project transition process on the IT operational effectiveness at the SAGOV. Do you agree or disagree with this statement and to what extent?

2. Do you agree with the project selection based on the criteria explained earlier?

3. How the implementation process varied in IT projects which resulted in varying levels of success in terms of meeting the business and operational objectives?

4. What did the organization learn from its implementation experiences and what were the difficulties in applying the best practices to achieve the desired business and operational outcomes across all projects? 
5. Were improved practices applied on subsequent projects? How much did it influence the operational efficiency?

6. What were the main difficulties in supporting the production applications?

7. What were the reasons behind most operational bottlenecks?

8. Why was the project delivery team unable to provide the required support to operations team?

9. What was the best level to collaborate for maximum reduction of the problems: the management level or the technical resource level?

10. How can project resources be involved in the operations support?

11. Which of the following is the most significant requirement of the project delivery team for meeting the operational outcomes:

a) operations' staff trainings on the applications by the project team

b) end-user trainings by the project staff

c) extended support by the project delivery team to the applications in production

12. Is it possible to implement a process which will eliminate the need of project resources?

13. What documentation from the project implementation phase is required for operations support?

14. Can the support documentation alone serve the purpose under various circumstances? If not, why so?

15. How can the end-users be involved in project life cycle for more effective operational outcomes?

\section{Authors}

Yaser Mirza is an IT professional and technology entrepreneur with over a decade experience working in public and private sector. He is currently working as an IT Manager in Government of Australia. He is also a doctoral student at the School of Information Technology and Mathematical Sciences at University of South Australia. He received his Master's degree in IT with specialization in Data Management from Griffith University Australia and Bachelors of Engineering in Computer Software Engineering from National University of Science and Technology in Pakistan. His research interests include IT Strategy, Digital Innovation and Human Computer Interaction.

Baber Majid Bhatti is an IT strategist, planner, implementer and optimizer having seventeen years of professional experience mainly in the ICT industry. He has worked in the Asia-Middle East, Asia-South East, Asia-Pacific including China, United States, Central West Africa, Europe and Australia in various roles including CIO, CTO, General Manager, Program Manager, Strategist and Management Consultant. He received his Master in Computer Science from LUMS (Lahore University of Management Sciences) and Bachelor of

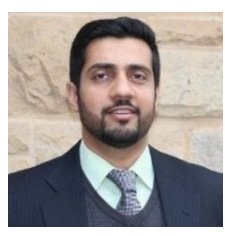
Engineering from UET (University of Engineering and Technology), Lahore. He is currently pursuing his PhD in IT Strategy from University of South Australia. His research interests include IT Strategy, IT Policies, Managed Services, Outsourcing, and IT Risk Management. 